\title{
Cuckoo Search Algorithm for Congestion Alleviation with Incorporation of Wind Farm
}

\author{
Kaushik Paul, Niranjan Kumar \\ Department of Electrical and Electronics Engineering, National Institute of Technology Jamshedpur, India
}

\begin{tabular}{l} 
Article Info \\
\hline Article history: \\
Received Mar 19, 2018 \\
Revised Jul 18, 2018 \\
Accepted Jul 29, 2018 \\
\hline
\end{tabular}

\section{Keyword:}

Cost function

Generator rescheduling

Optimization

Power flow

Renewable energy

\begin{abstract}
The issue to alleviate congestion in the power system framework has emerged as an alluring field for the power system researchers. The research conducted in this article proposes a cuckoo search algorithm-based congestion alleviation strategy with the incorporation of wind farm. The bus sensitivity factor data are computed and utilized to sort out the sutiable position for the installation of the wind farm. The generators contributing in the real power rescheduleing process are selected as per the generator sensitivity values. The cuckoo search algorithm is implemented to minimize the congestion cost with the embodiment of the wind farm. The proposed method is tested on 39 bus New England framework and the results obtained with the cuckoo search-based congestion management approach outperforms the results opted with other heuristic optimization techniques in the past research literatures.
\end{abstract}

Copyright $@ 2018$ Institute of Advanced Engineering and Science. All rights reserved.

\section{Corresponding Author:}

Kaushik Paul,

Department of Electrical and Electronics Engineering,

National Institute of Technology Jamshedpur,

Jharkhand, India 831014.

Email: kaushik.2014rsee002@nitjsr.ac.in

\section{INTRODUCTION}

The issue of congestion alleviation in the power system framework has gained the interest of several researchers in the recent times. A transmission line in power system network is said to be overburdened when the transfer of power from one point to the other is compromised due to the violation of the transfer limits [1]. An efficient Congestion Management (CM) approach will lead to a reliable and stable operation of the power system framework. Neumerous numbers of methodologies and procedures have been proposed by the researchers to manage the congestion. A detailed survey of several CM approaches can be found in [2], [3]. Mishra and Kumar performed CM considering the optimal placement and sizing of the Inter line Power Flow Controller (IPFC) with the application of Gravitational Search Algorithm (GSA) [4]. In another research Eshafani et al. utilized the thermal rating of the transmission framework and formulated a real time CM [5]. Hemmati et al. formulated the CM strategy by the optimal scheduling of the energy storage system [6]. Reddy designed an optimal power flow problem based on the pool and bilateral contracts with the optimal location of FACTs devices to mitigate congestion [7].

The wide use of the renewable energy resources have aimed towards the pollution free society. This initiative has inspired the power system researchers to explore the various oppourtunities associated with the renewable form of energy resources to manage the several power system problems [8]. The usefulness of the wind energy and its application in the sector of power system can be found in [9]. Fiejoo and Cidras came forward with their research of modeling and analyze the influence of the wind farm to manage the power flow in transmission framework [10]. Nesamalar et al. studied the effect of conventional energy resources in association with the renewable energy resources based on the locational marginal pricing to attenuate the over burden of the transmission lines [11]. Vargas et al. linked the wind energy along with the battery energy 
staorage system to manage congestion considering the ramp rates of the power plants [12]. The rescheduling of the generators is one of the primitive measures adopted to control congestion. Fang et al. designed a optimal rective power dispatched problem considering the rescheduling of the generators [13]. Othman et al. sorted the critical generator to schedule their power delivery to maintain the available transfer capability [14]. Yesuratnam and Thukaram formulated Relative Electrical Distance (RED) to select the generator participating in the rescheduling process to attenuate the over burden of the transmission line [15]. Sudipta and Singh implemented Particle Swarm Optimization (PSO) to minimize the congestion cost involved in generator rescheduling to managing congestion. The generators contributed in the rescheduling process were selected based on the Generator Sensitivity Factor (GSF) [16]. Deb and Goswami formulated CM approach with wind energy resource and Artificial Bee Colony (ABC) to optimize the congestion cost [17].

Kallam et al. in their research utilized Cuckoo Search Algorithm (CSA) to optimally design the control parameters for the grid connected photovoltaic system and the CSA was found to be better than the genetic and bacterial foraging algorithm [18]. In another research Dalali and Karegar introduced CSA and found the performance of CSA to be appreciative for the optimal placement of the Phasor Measurement Unit (PMU) [19]. The optimal power flow problem with the integration of wind energy was performed by Mishra et al. using CSA and the outcomes achieved with CSA was better when compared to the results obtained with PSO [20]. Abarghooee et al. designed a multi-objective problem for the scheduling of the thermoelectric power system with CSA. The performance of CSA was found to be versatile than PSO, Differential Evolution (DE) and Non Dominated Sorted Genetic Algorithm (NSGA) [21]. Fergany et al. determined the optimal location of the capacitor and minimization of the operating cost with the incorporation CSA [22]. Vo et al. designed a economic load dispatched considering valve point effect and implemented CSA and found that CSA performed better than PSO [23].The above referred literatures signify the versatility of CSA over other optimization algorithms and it can be anticipated that CSA will also provide better outcomes for the proposed CM approach.

In this paper a formulation of CM strategy is projected to analyze the combined effect of the wind farm for the CM with generator rescheduling. The integral intent of the proposed work is to extend CSA as an efficient optimization approach to minimize the cost of congestion with the incorporation the wind farm and adeptly expel the congested line from the over burden condition. The Bus Sensitivity Factor (BSF) is utilized to identify the buses for the placement of the wind farm. The participation of the generator in the CM scheme is considered based on the GSF values. The potency of the proposed approach is validated on the 39 bus New England system. The outcomes achieved with CSA are compared with the results of RED, PSO and $\mathrm{ABC}$ optimization algorithms referred in the past literatures [15]-[17] respectively.

\section{RESEARCH METHOD}

\subsection{Wind Farm}

The determination of the injected power is estimated based on the Fixed Speed Wind Turbine Generating Unit (FSWTGU) model of power flow. In case of the induction machine, the stator terminals hold the position of the capacitors at the time of its functioning as induction generator and it is self energized inspite of the fact that power electronic converters are at times utilized. In case of fetching of the real power or in the situation of the reactive power withdrawal, the capacitors are used to enhance the improvement in the power factor and loss reduction. The wind farm model is shown in the Figure 1 [10]. The induction generator parameters corresponding to the wind farm are considered as follows: Rated voltage $=660 \mathrm{~V}, \mathrm{R}_{\mathrm{s}}=$ $0.00708 \Omega, \mathrm{X}_{1}=0.07620 \Omega, \mathrm{X}_{\mathrm{m}}=3.4497 \Omega, \mathrm{X}_{2}=0.23297 \Omega$ and $\mathrm{R}_{\mathrm{R}}=0.00760 \Omega$.

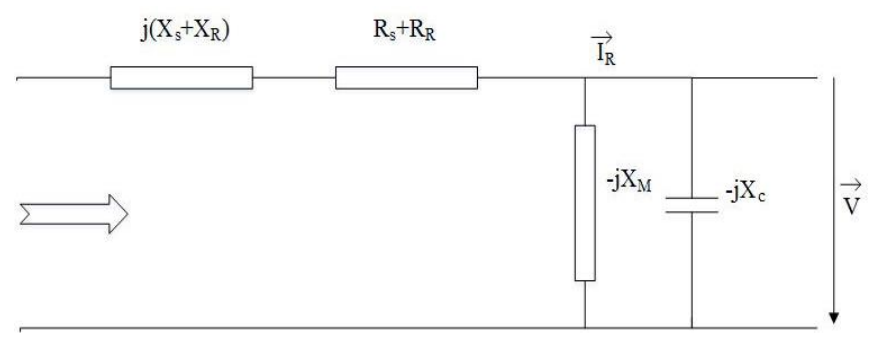

Figure 1. Representaion of wind farm model

The equation for the consumption of reactive power in case of wind farm can be represented as [10]: 


$$
\begin{aligned}
& Q=V^{2} \frac{X_{c}-X_{m}}{X_{c} X_{m}}+X \frac{V_{2}+2 R P}{2\left(R^{2}+X^{2}\right)}-X \frac{\sqrt{\left(V^{2}+2 R P\right)-4 P^{2}\left(R^{2}+X^{2}\right)}}{2\left(R^{2}+X^{2}\right)} \\
& Q=V^{2} \frac{X_{c}-X_{m}}{X_{c} X_{m}} \frac{X}{V^{2}} \mathrm{P}^{2}
\end{aligned}
$$

$\mathrm{V}$ : rated voltage.

$\mathrm{P}$ : injected active power in the grid.

$\mathrm{X}$ : stator and rotor leakage reactances in total.

$\mathrm{X}_{\mathrm{c}}$ : capacitor bank reactances.

$\mathrm{R}$ : summation of both the reactances of stator and rotor.

The real power of FSWTGU is given by [10],

$$
P=\frac{1}{2} \rho A U^{3} C_{P}
$$

where the area of the rotor is represented by A, air density is designated as $\rho, \mathrm{U}$ represents the speed of the wind and $\mathrm{C}_{\mathrm{P}}$ is designated as the power co efficient.

\subsection{Cuckoo Search Algorithm}

The CSA algorithm was formulated by Yang and Deb in the year 2009 and it depends on the following idealized rules. i) a single egg is laid by the cuckoo and it randomly drops the egg in a selected nest. ii) the nest having the good quality of egg will be considered for subsequent generations. iii) the numeric count of the host nest is constant and an effort is made by the host bird to detect the laid eggs [18]. The cuckoo birds are one of the most fascinating and intelligent birds. They lay eggs (solution) in the other bird's nest. The cuckoo bird explores for the high survival of their eggs and finds the most appropriate nest to lay their eggs. The eggs (close to optimal value) exhibiting similarity as per the host bird eggs have a high probability to flourish into a mature cuckoo. The eggs which are identified with a probability of $\mathrm{Pa} \epsilon[0,1]$ as the foreign eggs (not optimal value) by the host bird are either tossed off or the host bird moves away and builds another nest. The nest location is randomly opted by the cuckoo to lay their egg using equation (4) and (5)

$$
\begin{aligned}
& X_{p q}^{g e n+1}=X_{p q}^{g e n+1}+s_{p q} \times \operatorname{Levy}(\lambda) \times \alpha \\
& \operatorname{Levy}(\lambda)=\left|\frac{\Gamma(1+\lambda) \times \sin \left(\frac{\pi \times \lambda}{2}\right)}{\Gamma\left(\frac{1 \times \lambda}{2}\right) \times \lambda \times s^{(\lambda-1) / 2}}\right|
\end{aligned}
$$

The value of $\lambda$ ranges from $(0.25<\lambda<3)$ along with the value of $\alpha$ taken randomly in the range of $[-1,1]$. The value of $S$ is taken as per the interest of the problem. The value of $S$ is always greater than 0 . The step size is given by equation (6).

$$
s_{p q}=X_{p q}^{g e n}-X_{f q}^{g e n}
$$

where $p, f \in[1,2, \ldots . n]$ and $q \epsilon[1,2, \ldots . n]$ are considered for the proposed case.. The host bird finds out the foreign egg by establishing a random comparison between $\mathrm{P}_{\mathrm{a}}$ and $\mathrm{Pro}_{\mathrm{p}}$. The probability Pro $_{\mathrm{p}}$ is given by:

$$
\operatorname{pro}_{p}=\left(\frac{0.9 \times f i t_{p}}{\max (f i t)}\right)+0.1
$$

The discovery of the egg will led to the throwing of the egg from the nest or the host bird will opt for a new nest while abandoning the previous one and manufacture a new nest given by equation (8). 
${ }^{n e s t} t_{p}=X_{p, \min }+\operatorname{rand}(0,1) \times\left(X_{p, \max }-X_{p, \min }\right)$

The nest nuber are taken as 90 . The rate of alien egg discovery $=0.25$, Levy flight coefficient $=0.5$. Iterations $=100$. The pseudo code of CSA for CM is shown in Figure 2.

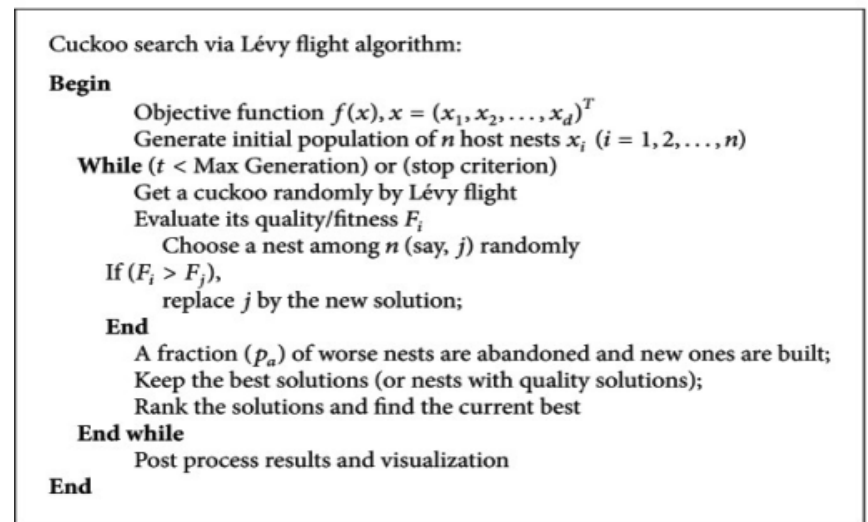

Figure 2. Pseudocode of Cuckoo search algorithm for congestion management

\subsection{BSF Calculations}

The real power flow is designated as:

$$
P_{i j}=-\left|V_{i}\right|\left|V_{j}\right|\left|Y_{i j}\right| \cos \left(\theta_{i j}-\delta_{i}+\delta_{i}\right)-V_{i}^{2} Y_{i j} \cos \theta_{i j}
$$

The components $V_{i}, \Theta_{i} \Theta_{i j}, Y_{i j}$ are designated as the voltage magnitude, angle of the $i^{\text {th }}$ bus, magnitude and angle of the $\mathrm{ij}^{\text {th }}$ element of the $\mathrm{Y}_{\mathrm{BUS}}$ matrix respectively. The BSF is termed as the ratio of the difference in power flow $\Delta \mathrm{P}_{\mathrm{ij}}$ in a line to the change in the active power injection $\Delta \mathrm{P}_{\mathrm{n}}$ at bus $\mathrm{n}$. The $\mathrm{BSF}$ for the $\mathrm{k}^{\text {th }}$ line is is given as:

$$
\operatorname{BSF}_{n}^{k}=\Delta P_{i j} / \Delta P_{n}
$$

In case of a over burdened line the expression for the BSF is given by:

$$
B S F_{n}^{k}=a_{i j} m_{i n}+b_{i j} m_{j n}
$$

The detail derivation of BSF can be found in [17].

\section{PROBLEM FORMULATION}

The design of the objective function to evaluate the congestion cost depending upon the amount of real power rescheduled is given by:

$$
\text { Minimize } \sum_{g=1}^{N_{g}} C_{g}\left(\Delta P_{g}\right) * \Delta P_{g}
$$

$\mathrm{C}_{\mathrm{g}}, \mathrm{P}_{\mathrm{g}}$ and $\mathrm{N}_{\mathrm{g}}$ are the price bids of the generators, amount of the rescheduled real power and count in the participating generator in the CM respectively.The GSF constraint is given by: 




The Ramp limit:

$$
\mathrm{P}_{\mathrm{g}}-\mathrm{P}_{\mathrm{g}}^{\min }=\Delta \mathrm{P}_{\mathrm{g}}^{\text {min }} \leq \Delta \mathrm{P}_{\mathrm{g}} \leq \Delta \mathrm{P}_{\mathrm{g}}^{\max }=\mathrm{P}_{\mathrm{g}}^{\max }-\mathrm{P}_{g}
$$

Power balance:

$$
\sum_{i=1}^{N g} \Delta P_{G i}=0
$$

$\mathrm{P}_{\mathrm{g}}^{\min }$ and $\mathrm{P}_{\mathrm{g}}^{\max }$ corresponds to the limits of the generator g's minimum and maximum active power generation. $F_{k}^{0}$ corresponds to the flow of the power in the $\mathrm{k}^{\text {th }}$ transmission line resulted due to all the contacts requesting the transmission service. $F_{k}^{\max }$ corresponds to the MVA flow limit of the transmission line $\mathrm{k}$ joining the buses $\mathrm{i}$ and $\mathrm{j}$.

\section{RESULTS AND DISCUSSIONS}

In this article the CM strategy is modeled with the integration of the wind farm to the most sensitive bus and CSA is also applied to minify the congestion cost. The entire simulation is performed on MATLAB 2016b. The framework of 39 bus New England is considered to test the effectiveness of the proposed strategy adopted for the CM. The 39 bus New England framework bears 10 generator buses and 29 buses as the load buses and its pictorial representation is shown in Figure 3.

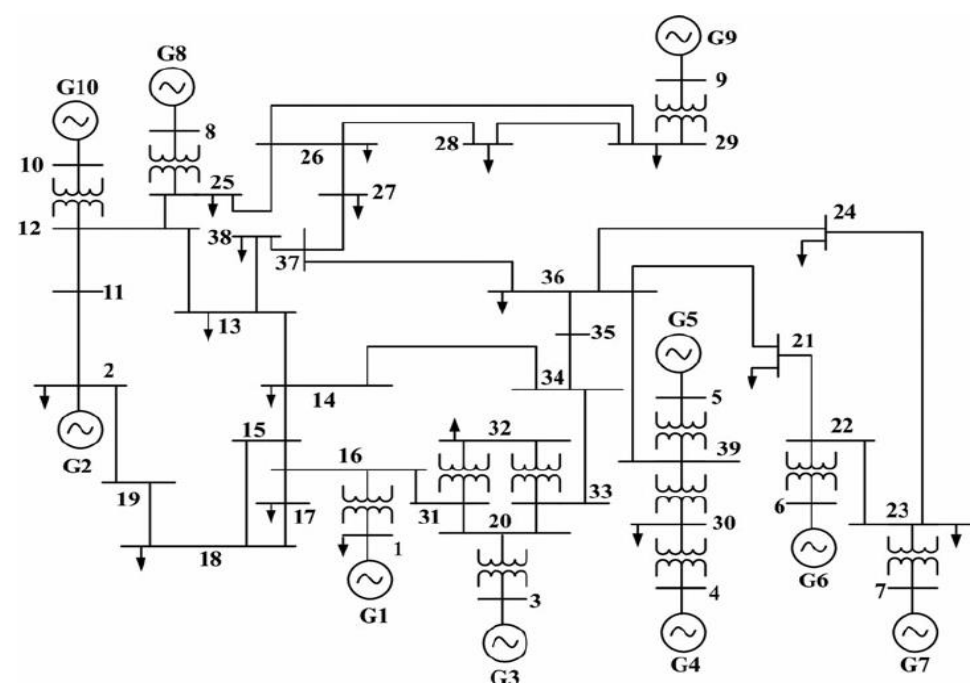

Figure 3. Framework of 39 bus New England System

The wind farm parameters are taken from the article [10]. The congestion is established in the line 15-16 with the outage of the line between the bused 14-13. The outage has led to the increment in the flow to 628 MVA leading to the overburdening of the line 15-16 and the flow limit of the line is 500 MVA. Table 1 represents the BSF values for the congested line 15-16. The bus number 14 and 34 exhibits strong BSF values and the wind farm location is designated at bus 14 which exhibit the most negative BSF. 
Table 1. BSF values with different wind farm power level with outage of line 14-34

\begin{tabular}{ccccc}
\hline Bus No & $\begin{array}{c}\text { Without } \\
\text { Wind farm }\end{array}$ & $\begin{array}{c}\text { Bus Sensitivity Factor Values } \\
\text { With Wind } \\
\text { Farm (30MW) }\end{array}$ & $\begin{array}{c}\text { With Wind } \\
\text { Farm (50MW) }\end{array}$ & $\begin{array}{c}\text { With Wind } \\
\text { Farm (100MW) }\end{array}$ \\
\hline 1 & 0 & 0 & 0 & 0 \\
8 & -0.0199 & -0.0206 & -0.0197 & -0.0194 \\
9 & 0.0296 & 0.0289 & 0.0292 & 0.0290 \\
10 & -0.0398 & -0.0387 & -0.0384 & -0.0380 \\
12 & -0.0399 & -0.0379 & -0.0374 & -0.0370 \\
14 & -0.2572 & -0.2496 & -0.2494 & -0.2491 \\
16 & -0.0051 & -0.0024 & -0.0021 & -0.0020 \\
19 & -0.0337 & -0.0295 & -0.0292 & -0.0289 \\
25 & -0.0218 & -0.0213 & -0.0210 & -0.0204 \\
27 & 0.0488 & 0.0498 & 0.0511 & 0.0516 \\
34 & 0.4176 & 0.4244 & 0.4251 & 0.4302 \\
38 & 0.0205 & 0.0234 & 0.0236 & 0.0240 \\
\hline
\end{tabular}

A gradual reduction in the level of the power flow is observed in the over burdened line 15-16 with the increment the rating of the wind farm from $30 \mathrm{MW}$ to $100 \mathrm{MW}$ placed at bus 14 . This resulted in the curtailment in the number of participating generators in CM. Table 2 shows the reduction in the flow of power in line 15-16 with various level of wind farm. The research presented in this paper is conducted considering the $30 \mathrm{MW}$ wind farm. It is to be noted that a higher rating of the wind farm will also reduce the over burden of the power flowing in the line and curtail the cost involved in the rescheduling process but it is also to be noted that the cost and space to accommodate a large wind farm is huge. Thus, due to these issues $30 \mathrm{MW}$ wind farm is considered for the research purpose.

Table 2. Power Flow in the Congested line 15-16

\begin{tabular}{lcccc}
\hline & \multirow{2}{*}{ Without wind farm } & \multicolumn{3}{c}{ With wind farm at different power level } \\
& \multirow{2}{*}{$30 \mathrm{MW}$} & $50 \mathrm{MW}$ & $100 \mathrm{MW}$ \\
\hline Power flow (MVA) & 628 & 603 & 587 & 548 \\
\hline
\end{tabular}

Table 3 represents the GSF values at different power level of the wind farm corresponding to the congested line. Uniform GSFs are observed for the different wind farm power levels for the generator $2,4,5,6,7,8$. This signifies that these generators contribute similar effect towards the congested line. The nonuniform GSFs are shown by 3,9 and 10 generators and these three generators are considered to contribute towards the CM. This approach led to the reduction in the generator numbers. In this research the $30 \mathrm{MW}$ wind farm is opted to manage congestion. The price bids for the generators are given in Table 4.

Table 3. GSF values with different wind farm power level with outage of line 14-34

\begin{tabular}{ccccc}
\hline Bus No & $\begin{array}{c}\text { Without Wind } \\
\text { farm }\end{array}$ & $\begin{array}{c}\text { Generator Sensitivity Factor } \\
\text { With Wind } \\
\text { Farm (30MW) }\end{array}$ & $\begin{array}{c}\text { With Wind } \\
\text { Farm }(50 \mathrm{MW})\end{array}$ & $\begin{array}{c}\text { With Wind Farm } \\
(100 \mathrm{MW})\end{array}$ \\
\hline 1 & 0 & 0 & 0 & 0 \\
2 & -0.5621 & -0.5561 & -0.5552 & -0.5521 \\
3 & -0.0787 & -0.0823 & -0.0814 & -0.0792 \\
4 & -0.4077 & -0.4192 & -0.4189 & -0.4162 \\
5 & -0.4102 & -0.4110 & -0.4181 & -0.4172 \\
6 & -0.4134 & -0.4146 & -0.4138 & -0.4118 \\
7 & -0.4112 & -0.4119 & -0.4117 & -0.4196 \\
8 & -0.5524 & -0.5528 & -0.5518 & -0.5589 \\
9 & -0.5029 & -0.5048 & -0.5034 & -0.5020 \\
10 & -0.5948 & -0.5951 & -0.5889 & -0.5881 \\
\hline
\end{tabular}

Table 4. Generator price bids for 39-bus New England Test System (\$/MW-Day)

\begin{tabular}{cccccc}
\hline Gen No. & 1 & 2 & 3 & 4 & 5 \\
\hline Bids & 15 & 20 & 17 & 16 & 12 \\
Gen No. & 6 & 7 & 8 & 9 & 10 \\
Bids & 17 & 13 & 11 & 14 & 19 \\
\hline
\end{tabular}


Table 5 shows the comparative analysis of the outcomes achieved with CSA. The proposed CSA is adopted to minify the congestion cost and release the over burden of the transmission line with the introduction of the wind farm. The congestion cost achieved with the CSA is 5998.3 \$/day and is minimum when compared to the other cost obtained with RED, PSO and ABC optimization methodologies referred in [15]-[17] respectively. The losses are also reduced to 58.63 MW from 59.39 MW after the application of proposed CSA for the CM approach adopted with wind farm. Figure 4 shows the comparative analysis of the congestion cost achieved with different algorithms. The comparative analysis of the real power rescheduled with different algorithms is represented in Figure 5. The convergence profile is shown in Figure 6. The convergence characteristic seems to be promising in obtaining the optimal congestion cost with the proposed approach. Figure 7 shows the voltage level at different buses post CM. It is observed that the voltage levels are maintained within proper limits.

Table 5. Comparison of results for 39 bus New England framework

\begin{tabular}{ccccc}
\hline & & \multicolumn{2}{c}{ Amount of Rescheduling (MW) } & \\
& RED [15] & PSO [16] & ABC [17] & CSA [proposed] \\
\hline $\begin{array}{c}\text { Approx. Cost of } \\
\text { generator rescheduling } \\
\text { (\$/day) }\end{array}$ & 8639.1 & 8872.9 & 6448.3 & 5998.3 \\
$\begin{array}{c}\text { Power flow post CM. } \\
\text { Line 15-16 (MW) }\end{array}$ & 510 & & & \\
Gen No. & & 490 & 499.6 & 498.96 \\
1 & -99.59 & -149.1 & & \\
2 & 98.75 & 65.6 & Not Participated & Not Participated \\
3 & -159.64 & -129 & -48.54 & -39.7 \\
4 & 12.34 & Not Participated & Not Participated & Not Participated \\
5 & 24.69 & Not Participated & Not Participated & Not Participated \\
6 & 24.69 & Not Participated & Not Participated & Not Participated \\
7 & 12.34 & Not Participated & Not Participated & Not Participated \\
8 & 24.69 & 75.4 & Not Participated & Not Participated \\
9 & 12.34 & 52.1 & 6.96 & 53.15 \\
10 & 49.38 & 83.0 & 181.31 & 129.00 \\
& 518.45 & 554.2 & 375.53 & 360.47 \\
\hline
\end{tabular}

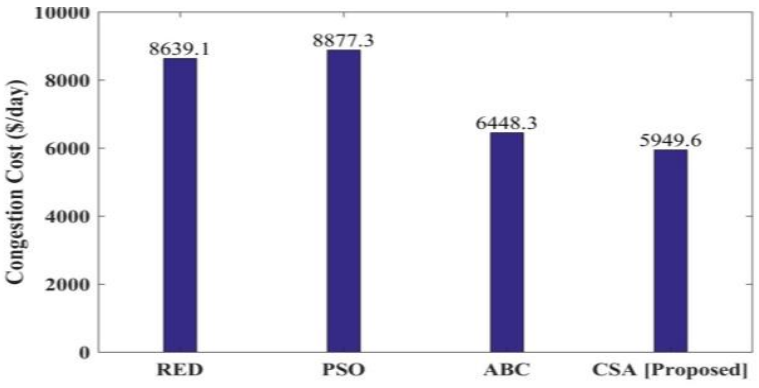

Figure 4. Comparison of congestion cost with other algorithm

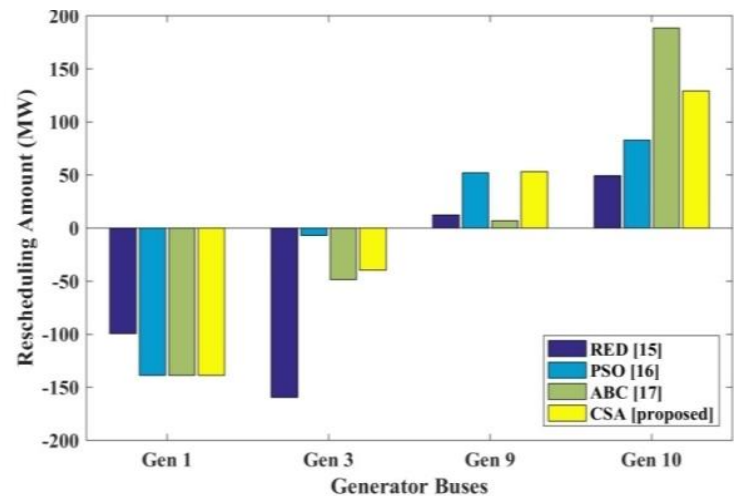

Figure 5. Rescheduling amount with different algorithm 


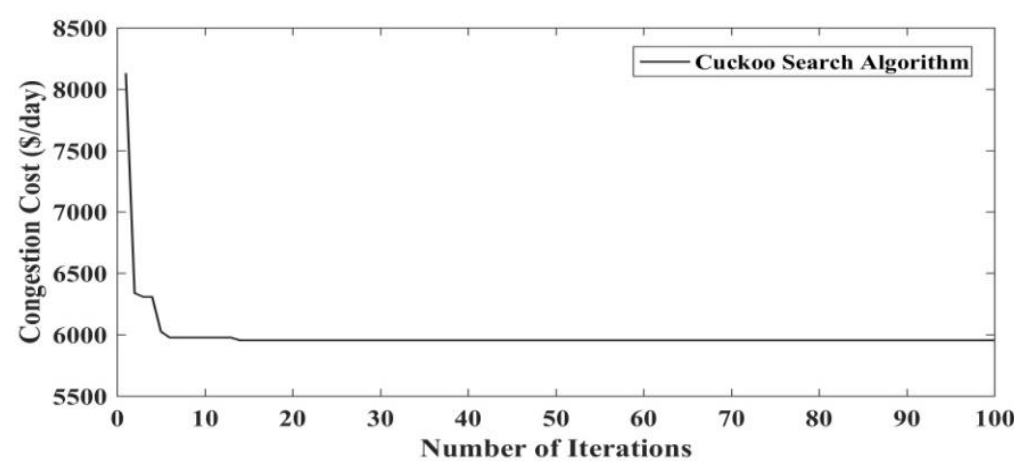

Figure 6. Convergence profile for CSA based approach with wind farm

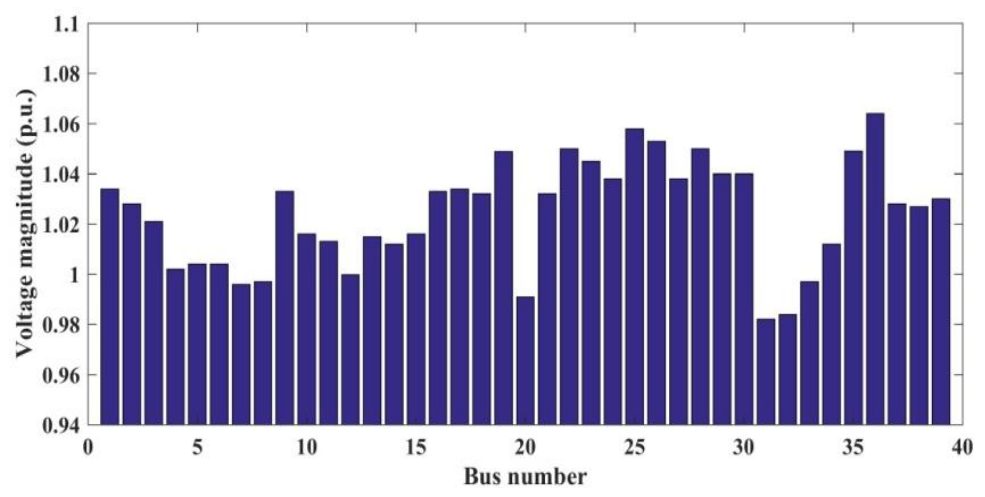

Figure 7. Bus voltages post rescheduling with CSA

\section{CONCLUSION}

This research article portrays the application of a nature inspired optimization algorithm for the alleviation of congestion with the implementation of the wind farm. The results obtained with the CSA have been compared with other optimization techniques reported in past research articles and are found to be more efficient and economical. It is found that CSA acts as an efficient optimizing approach in relieving the overburden of the transmission lines with the embodiment of the wind farm and enables the system operator to maintain the security and reliability of the system.

\section{REFERENCES}

[1] Ch. N. R. Kumari and K. C. Shekhar, "Optimal Placement of TCSC Based on Sensitivity Analysis for Congestion Management," International Journal of Electrical and Computer Engineering, vol/issue: 6(5), pp.2041-2047, 2016.

[2] A. Pillay, et al., "Congestion management in power systems - A review," International Journal of Electrical Power \& Energy Systems, vol. 70, pp. 83-90, 2015

[3] N. I. Yusoff, et al., "Congestion management in power system: A review," 3rd International Conference on Power Generation Systems and Renewable Energy Technologies (PGSRET), Johor Bahru, pp. 22-27, 2017.

[4] A. Mishra and V. N. Kumar G., "Congestion management of deregulated power systems by optimal setting of Interline Power Flow Controller using Gravitational Search algorithm," Journal of Electrical Systems and Information Technology, vol/issue: 4(1), pp. 198-212, 2017.

[5] M. M. Esfahani, et al., "Adaptive real-time congestion management in smart power systems using a real-time hybrid optimization algorithm," Electric Power Systems Research, vol. 150, pp. 118-128, 2017.

[6] R. Hemmati, et al., "Stochastic planning and scheduling of energy storage systems for congestion management in electric power systems including renewable energy resources," Energy, vol. 133, pp. 380-387, 2017.

[7] S. S. Reddy, "Optimal Placement of FACTS Controllers for Congestion Management in the Deregulated Power System," International Journal of Electrical and Computer Engineering, vol/issue: 8(3), pp. 1336-1344, 2018.

[8] H. Schermeyer, et al., "Renewable energy curtailment: A case study on today's and tomorrow's congestion management," Energy Policy, vol. 112, pp. 42 436, 2018.

[9] B. Benlahbib, et al., "Wind farm management using artificial intelligent techniques," International Journal of Electrical and Computer Engineering, vol/issue: 7(3), pp. 1133-1144, 2017. 
[10] A. E. Feijoo and J. Cidras, "Modeling of wind farms in the load flow analysis," IEEE Transactions on Power Systems, vol/issue: 15(1), pp. 110-115, 2000.

[11] J. J. D. Nesamalar, et al., "Optimal Utilization of Renewable Energy Sources for Congestion Management," IFACPapersOnLine, vol/issue: 48(30), pp. 264-269, 2015

[12] L. S. Vargas, et al., "Wind Power Curtailment and Energy Storage in Transmission Congestion Management Considering Power Plants Ramp Rates," IEEE Transactions on Power Systems, vol/issue: 30(5), pp. 2498-2506, 2015.

[13] S. Fang, et al., "Interval optimal reactive power reserve dispatch considering generator rescheduling," IET Generation, Transmission \& Distribution, vol/issue: 10(8), pp. 1833-1841, 2016.

[14] M. M. Othman and S. Busan, "A Novel Approach of Rescheduling the Critical Generators for a New Available Transfer Capability Determination," IEEE Transactions on Power Systems, vol/issue: 31(1), pp. 3-17, 2016.

[15] G. Yesuratnam and D. Thukaram, "Congestion management in open access based on relative electrical distances using voltage stability criteria," Electric Power Systems Research, vol/issue: 77(12), pp. 1608-1618, 2007.

[16] S. Dutta and S. P. Singh, "Optimal Rescheduling of Generators for Congestion Management Based on Particle Swarm Optimization," IEEE Transactions on Power Systems, vol/issue: 23(4), pp. 1560-1569, 2008.

[17] S. Deb, et al., "Congestion Management Considering Wind Energy Sources Using Evolutionary Algorithm," Electric Power Components and Systems, vol/issue: 43(7), pp. 723-732, 2015.

[18] R. N. Kalaam, et al., "Optimisation of controller parameters for grid-tied photovoltaic system at faulty network using artificial neural network-based cuckoo search algorithm," IET Renewable Power Generation, vol/issue: 11(12), pp. 1517-1526, 2017.

[19] M. Dalali and H. K. Karegar, "Optimal PMU placement for full observability of the power network with maximum redundancy using modified binary cuckoo optimisation algorithm," IET Generation, Transmission \& Distribution, vol/issue: 10(11), pp. 2817-2824, 2016.

[20] C. Mishra, et al., "Optimal power flow in the presence of wind power using modified cuckoo search," IET Generation, Transmission \& Distribution, vol/issue: 9(7), pp. 615-626, 2015.

[21] R. A. Abarghooee, et al., "Multi-objective short-term scheduling of thermoelectric power systems using a novel multiobjective $\theta$-improved cuckoo optimisation algorithm," IET Generation, Transmission \& Distribution, vol/issue: 8(5), pp. 873-894, 2014.

[22] A. A. El-fergany and A. Y. Abdelaziz, "Capacitor allocations in radial distribution networks using cuckoo search algorithm," IET Generation, Transmission \& Distribution, vol/issue: 8(2), pp. 223-232, 2014.

[23] D. N. Vo, et al., "Cuckoo search algorithm for non-convex economic dispatch," IET Generation, Transmission \& Distribution, vol/issue: 7(6), pp. 645-654, 2013.

\section{BIOGRAPHIES OF AUTHORS}

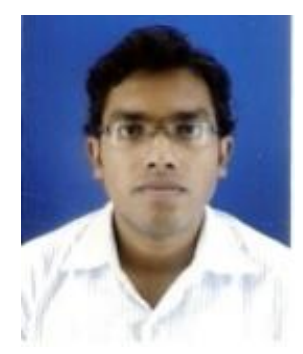

Kaushik Paul: He received his B. Tech degree in Electrical Engineering from West Bengal University of Technology in the year 2010 and receved his M.Tech degree in Electrical Engineering with specialization in Power System from National Institute of Technology Kurukshetra in the year 2012. He was an Assistant Professor in the department of Electrical Engineering in Sharda Group of Institutions, Agra for two years. Presently he is pursuing Ph.D. from National Institute of Technology Jamshedpur in the department of Electrical and Electronics Egineering. His research area includes power system deregulation, renewable energy, optimization techniques and smart grid.

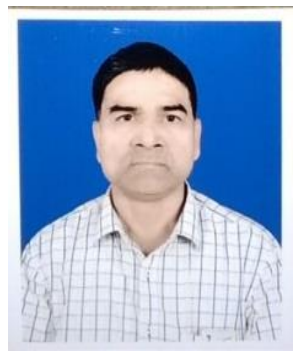

Niranjan Kumar: He received his B.Sc engineering inthe year 1988 and his M.Tech degree in the field of Eectrical engineering from Ntional Institute of Technology Jamshedpur in the year 1996. He completed his Ph.D degree from IIT Roorkee and his research areas include power system deregulation , transmission pricing and electricity market. 